\title{
POLÍTICA, FICÇÃO E "VERDADE", DE ANTONIO CALLADO AO ROMANCE BRASILEIRO CONTEMPORÂNEO
}

\author{
POR \\ Cristina Ferreira Pinto-Bailey \\ Washington and Lee University
}

O romance político brasileiro do século vinte teve em Antônio Callado um de seus maiores expoentes. Com seu romance Quarup, de 1967, um marco importante na nossa literatura, Callado realizou um projeto literário-político que até então tinha sido "frustrado", segundo o crítico Wilson Martins em artigo publicado no Suplemento literário de O Estado de São Paulo em 1968 (Leite 132). Quarup marcou época, estimulou debate e influenciou várias gerações de leitores. Chamado na época o "romance da revolução", a obra foi capaz de mobilizar para seus leitores, através da ficção, o sonho de um movimento político e social que havia sido interrompido pelo Golpe Militar de 1964 e que, a partir de 1968, com o recrudescimento da repressão política, parecia cada vez mais um projeto impossível de realizar-se.

Obra ambiciosa e complexa, Quarup não só representou um desejado processo de politicização da nação brasileira através do aprendizado político do protagonista, o Padre Nando, como também examinou minuciosamente a questão de uma identidade nacional, e expôs o desconhecimento do Brasil pelos brasileiros e a exploração destruidora da terra brasileira por um capitalismo que se exacerbaria com o arroxo das políticas econômicas do governo militar e dos governos civis que se seguiram depois de 1985 . Quarup exemplificou também, de modo singular, o importante papel que a literatura de ficção pode cumprir em um debate político, principalmente quando esse debate encontra-se banido do espaço público. Como Regina Dalcastagnè afirmou em um ensaio sobre o romance brasileiro contemporâneo, "a representação artística repercute no debate público, pois pode permitir um acesso à perspectiva do outro mais rico e expressivo do que aquele proporcionado pelo discurso político em sentido estrito" (19). Dalcastagnè examina como esse papel político se cumpre em obras publicadas na virada do século vinte e um; entretanto, já um quarto de século antes Callado construía em seus romances o espaço de reflexão, crítica e denúncia política que faltou na sociedade brasileira durante o período de repressão e censura da ditadura militar.

A partir de Quarup, Callado acompanhou e registrou o desenrolar dos acontecimentos políticos durante a ditadura militar nos romances que viriam a ser publicados depois: 
Bar Don Juan (1971), Reflexos do baile (1976), Sempreviva (1981), A expedição Montaigne (1982), Concerto carioca (1985) e Memórias de Aldenham House (1989), seu último romance. Memórias de Aldenham House afasta-se da trajetória iniciada com Quarup, ao enfocar um período anterior ao Golpe de 64, embora também trate de um período ditatorial no Brasil e na América espanhola, enquanto que a Europa -mais precisamente a Inglaterra, onde se passa a maior parte da ação narrativa- vive sob a ameaça nazista. Memórias de Aldenham House é um romance histórico-policial situado durante a ditadura de Getúlio Vargas, época em que outros países sul-americanos, como o Paraguai e a Bolívia -ambos representados no romance- viviam também sob regimes repressores. Nesta obra o autor delineia uma identidade nacional a partir de uma perspectiva transnacional latinoamericana, ao inserir o momento histórico-político nacional no contexto mais amplo da história do continente e das relações políticas entre o Brasil e seus vizinhos de língua espanhola, aspecto que, aliás, já aparecera em Bar Don Juan e Sempreviva.

Em Sempreviva, cuja ação narrativa tem lugar durante os últimos anos da ditadura militar, o protagonista, Quinho, deixa o exílio político na Europa para regressar ao Brasil clandestinamente e investigar evidências que comprovassem a cooperação ilícita entre os aparelhos de repressão brasileiro e os de países vizinhos, cooperação que se deu dentro do esquema da Operação Condor, rede de colaboração armada entre os governos e grupos de extrema direita do Brasil, Uruguai, Argentina, Chile e Paraguai, sob os auspícios do governo estadunidense. ${ }^{1}$

Quinho tinha sido encarregado pela Anistia Internacional de procurar elucidar o paradeiro de presos políticos e de ex-agentes da repressão, e suas investigações e inquirições revelam aos leitores o envolvimento do Brasil no desaparecimento de presos políticos dos países vizinhos, trazidos clandestinamente para solo brasileiro, onde permaneceriam presos, sofreriam tortura e poderiam ser assassinados. Sempreviva denuncia essa rede de cooperação escusa entre os países do Cone Sul em um momento em que o público em geral tinha pouco conhecimento sobre a Operação Condor. O romance é publicado nos últimos anos da ditatura militar brasileira, durante o governo do General João Batista Figueiredo (1979-1985), quando se implementa uma certa abertura democrática, apesar da resistência de segmentos da linha-dura dentro do próprio governo, que queriam impedir a distensão política. Neste sentido, vale lembrar o fracassado atentado do Riocentro, no dia 30 de abril de 1981, quando agentes da

1 Sobre a Operação Condor, ver John Dinges, The Condor Years: How Pinochet and His Allies Brought Terrorism to Three Continents (New York: New Press, 2004), and J. Patrice McSherry, Predatory States: Operation Condor and Covert War in Latin America (Lanham, MD: Rowman \& Littlefield, 2005). No romance $O$ punho e a renda (2010), Edgard Telles Ribeiro descreve a entranhada rede de maquinações, conluios e oportunismo que sustentaram a Operação Condor e de que fizeram parte eminentes membros do corpo diplomático brasileiro. 
linha-dura pretendiam fazer explodir bombas durante um concerto que celebrava o Dia do Trabalhador, para culparem elementos da esquerda.

Neste contexto, assim como em muitos outros momentos da história nacional, a encenação política teve por fim manipular a opinião pública e ocultar o conflito de poderes que frequentemente ocorre nos bastidores da política brasileira, deixando imprecisos perfis daqueles envolvidos. Essa manipulação da verdade espelha-se em romances de Callado, como Reflexos do baile e Sempreviva, em um jogo de máscaras que os personagens representam para o público leitor com o auxílio de um narrador não confiável. No caso de Sempreviva, por exemplo, o protagonista volta ao Brasil para tentar identificar vários homens implicados na tortura e morte de prisioneiros políticos, tanto brasileiros como hispanoamericanos levados clandestinamente para o Brasil pelas forças da repressão em seus países natais. Entretanto, a identificação desses agentes da repressão -torturadores e médicos legistas-, os quais vivem no interior do Brasil sob nomes falsos, revela-se uma charada muito mais difícil de resolver-se do que Quinho e seus amigos imaginavam:

[...] esse Dianuel, que parece ser a figura mais apagada e mais tola ..., a não ser que seja, naturalmente, o artista mais consumado entre todos eles? ... ou, se achou Dianuel insignificante achou talvez ... que você podia sondá-lo mais à vontade, descobrindo assim através dele, a respeito de Melquisedeque, a certeza de que ele seja quem nós praticamente juramos que é-Ari Knut? [...]

-Sim, dizia Jupira, nós sabemos [...] que Melquisedeque é Ari Knut-a menos, digo eu agora, que o Knut seja, quem sabe, Lino Mano, não? (Callado, Sempreviva 53)

Através desta ciranda de personagens cuja identificação categórica continuamente escapa ao protagonista, o autor problematiza a questão da verdade e, ao mesmo tempo, põe em evidência a função história e política que a obra de ficção pode desempenhar. Afiliando-se à linha narrativa de Callado, Edgard Telles Ribeiro vai afirmar neste sentido, muitos anos depois, na "Nota do autor" à primeira edição de $O$ punho e a renda: "Sou daqueles que acreditam que a ficção ainda é a melhor maneira de lidar com a realidade quando esta insiste em escapar ao escrutínio geral" (15).

Nenhum outro ficcionista brasileiro demonstrou mais consciência do que Callado quanto ao caráter evasivo daquilo que chamamos a "verdade", ainda mais quando o acesso a esta é vedado pela censura, pelo controle direto ou indireto dos meios de comunicação, ou ainda por várias formas de manipulação dos fatos e aparências utilizadas pelos detentores do poder. Assim, Callado articulou em sua obra estratégias narrativas que exigem leitores críticos, atentos e dispostos a desconstruir o jogo de máscaras montado sobre a polifonia, narradores não confiáveis e, às vezes, até uma escrita em código. Críticos como Lígia Chiappini M. Leite e Luiz Fernando Valente já comentaram o jogo de máscaras como elemento estruturador da narrativa em

-1] Revista Iberoamericana, Vol. LXXXVI, Núm. 271, Abril-Junio $2020, \quad 495-505$
ISSN 0034-9631 (Impreso) 
Sempreviva. Para Valente, esse jogo de identidades esquivas e incertas coloca em cheque os atos e comportamento dos personagens principais -visíveis aos olhos dos observadores- quando revelados seus motivos interiores -os quais os leitores vão pouco a pouco conhecendo, antes mesmo do protagonista e demais personagens-. Deste modo Sempreviva alerta os leitores "against deceptive appearances" (Valente 84), tal como o público brasileiro deveria estar atento contra manobras dissimuladas por parte do poder político. Já Leite caracteriza Sempreviva como uma narrativa que "se abre em leque, querendo não narrar, mas relembrar, desenterrar os fatos que ameaçam ficar sepultados nas senzalas de nós mesmos" (178), referindo-se ela aos eventos que a ditadura militar ocultou do público, e que ainda não tinham sido elucidados quando da publicação de Sempreviva.

Em Memórias de Aldenham House, Callado retoma certos elementos narrativos fundamentais em sua obra: a indagação crítica sobre a nacionalidade brasileira; a importância de registrar através da ficção a memória nacional e individual; e o papel da ficção como arquivo histórico e veículo de reflexão sobre a história. Desse modo, Memórias de Aldenham House vai constituir o monumento literário-histórico que a literatura, assim como outras formas de expressão artística, pode representar: "[...] um espaço cultural de enorme potência em relação aos restos, aos despojos, e às destruições do passado, proporcionando uma monumentalidade alternativa que, em tempos de comemorações declamatórias ou de embates ideológicos, torna-se indispensável resgatar" (Vecchi e Regina Dalcastagnè 12).

Em Memórias de Aldenham House, publicado já durante o período democrático que sucedeu à ditadura militar, o protagonista, Perseu Blake de Souza, percorre um trajeto oposto ao de Quinho de Sempreviva, deixando o Brasil sob a ditadura de Getúlio Vargas para o exílio na Inglaterra, onde irá trabalhar na Aldenham House da BBC, espécie também de memorial a uma América Latina explorada por séculos de colonização e neocolonização estrangeira, e controlada por governos ditatoriais de direita. Já durante a viagem que Perseu e outro latinoamericano, o paraguaio Facundo, fazem de navio para o exílio em solo inglês, inicia-se um jogo de máscaras que continuará na Inglaterra e, mais tarde, de novo em países da América do Sul, em particular no Paraguai do ditador Higinio Moríñigo Martínez (1940-1948) e sua polícia paramilitar.

Em Memórias de Aldenham House, esse jogo de máscaras-de personas e motivações esquivas e mutáveis- revela-se ele próprio um jogo sem regras fixas, movendo-se do marco cronológico da Segunda Guerra Mundial ao passado histórico que aproximou -como inimigos- o Brasil e o Paraguai, por um lado e, por outro, o Paraguai e a Bolívia. Os personagens de Perseu e Facundo, e Facundo e o boliviano Miguel Busch, rememoram juntos os conflitos entre seus países durante a Guerra do Paraguai (18641870) e, mais tarde, a Guerra do Chaco (1932-1935), mas também aliam-se na crítica das ditaduras modernas e na esperança do retorno a governos democráticos.

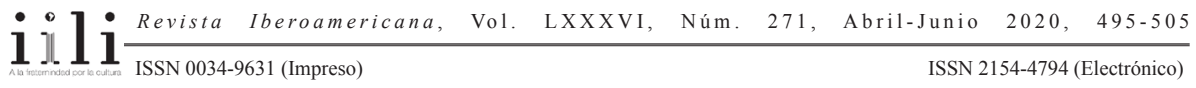


O jogo de máscaras estende-se também à própria narrativa, já que esta vai assumindo vários contornos, primeiro como romance de espionagem; logo como um "whodunit" ou seja, romance policial; e revelando-se finalmente uma narrativa trágica, uma encenação cruel montada pelo poder ditatorial de Morínigo contra Facundo. Este sofre a perseguição de seu governo primeiro na Inglaterra e, mais tarde, de modo ainda mais violento, desde o momento que retorna ao Paraguai. Ao chegar em Assunção, Facundo é imediatamente "convidado" a comparecer ao gabinete do chefe de polícia, o "Filinto Müller paraguaio" (Callado, Memórias 217), com a desculpa de ser necessário o cumprimento de uma simples formalidade. A partir de então, Facundo é psicológica e fisicamente agredido, preso sob falsa acusação mas sem julgamento, e termina "suicidando-se" em sua cela, sua morte um claro embuste político, sendo a verdade abafada na imprensa paraguaia e ele sepultado em um túmulo sem nome.

Ao contar o trágico desfecho de Facundo, o romance faz clara referência a tantos outros assassinatos de presos políticos em mãos de agentes da repressão, no Paraguai e em outros países latinoamericanos. Em particular, o "suicídio" de Facundo relembra claramente a morte do jornalista brasileiro Vladimir Herzog (1937-1975) na prisão, cujas circunstâncias ainda estariam longe de serem esclarecidas na época de publicação de Memórias de Aldenham House. Tal como no caso de Herzog, o discurso oficial caracterizou a morte de Facundo como suicídio por enforcamento; enquanto o assassinato de Herzog demorou mais de trinta anos para ser esclarecido, o de Facundo nunca chega a sê-lo, assim como tampouco se esclarece seu verdadeiro "crime": o de querer justiça e democracia para seu país.

A conclusão do romance ressalta a permanência -ou a insistência e periódico retorno- do estado de exceção no Brasil e em seus vizinhos de língua espanhola, ao retratar Perseu Blake de Souza uma vez mais na prisão, no final do ano de 1947, escrevendo em seu diário lembranças sobre Aldenham House, sobre a morte de Facundo, e sobre o assassinato de Miguel Busch pela repressão boliviana. A identidade da nação brasileira que se representa é portanto a de um país, como outros na América Latina, em um eterno jogo pendular entre forças ideológicas antagônicas, disfarçadas, no caso do Brasil, pela imagem da nação como "um país grande!" (Memórias 376; ênfase no original) e cordial, onde a máscara do carrasco pode rapidamente se metamorfosear em aparente amistosidade e vice-versa. Considerando o ano de publicação de Memórias de Aldenham House, e sua atualidade ainda hoje, o que vale destacar - e o que o romance problematiza de forma bastante explícita- é a manipulação da verdade, ao longo da história dos países latinoamericanos, pelo discurso oficial e pelas elites e os meios de comunicação que o apoiam:

Nos países dominados pelo imperialismo ninguém sabe muito bem, na hora, o que está acontecendo, por que e por quem as pessoas são mortas, por que se suicidam, quais são os motivos, a quem esses motivos aproveitam, cui bono. Nossa história fica um

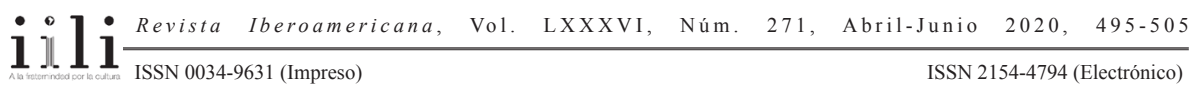


mistério insondável, porque vem pronta de fora. Ready-made. Uma falsa guerra civil matou Balmaceda. [...] Muitos Balmacedas ainda vão se matar, na América Latina. (Callado, Memórias 143)

Ao confrontar seus leitores com caleidoscópios de identidades e situações que vão se transformando de modo surpreendente aos nossos olhos, Callado mais uma vez nos conclama a indagar sobre a identidade nacional e sobre nossa própria posição como cidadãos frente a situações políticas de exceção ou, no mínimo, eticamente questionáveis. Esse questionamento, aliás, foi elemento fundamental em cada um de seus romances mas, principalmente, em Quarup e nos livros seguintes. Ao longo de sua obra o que parece ficar mais e mais evidente é a impossiblidade cada vez maior de uma resposta conclusiva, não tanto pela realidade discrepante de muitos Brasis que a nação engloba e representa (ou deveria representar), mas sim pela impossibilidade categórica de fixar-se uma "verdade" ou "a verdade".

Muitas das inquirições histórico-políticas que Callado explorou em seus romances ressurgem, dentro do marco de eventos políticos atuais, na obra de ficção de vários escritores brasileiros contemporâneos, destacando-se entre eles Ana Maria Machado, cuja obra romanesca apresenta também um projeto de indagação crítica sobre a identidade nacional, sobre questão do que é a "verdade", e o papel da obra de ficção como registro da memória e história nacionais. Autora de dez romances para adultos, além de mais de cento e cinquenta obras infanto-juvenis e vários outros livros de ensaio e poesia, Machado tem examinado em sua narrativa de ficção a importância da história e da memória na formação da identidade do sujeito e da identidade nacional. Além disso, seus romances oferecem uma constante reflexão crítica sobre o fazer literário e o olhar perscrutador que aquele lança sobre a realidade. Para Machado, a prosa de ficção permite examinar a história nacional a partir de perspectivas poucas vezes presentes na historiografia oficial ou na grande imprensa. De fato, embora todos seus romances sejam eminentemente políticos no sentido mais amplo da palavra, obras como Tropical sol da liberdade (1988), que trata de eventos ocorridos durante a ditadura militar brasileira, contrapõem-se explicitamente ao que poderia chamar-se de uma "política da amnésia" (Sapriza 96) favorecida pelo discurso oficial.

Como Callado, a ficção de Machado realiza um duplo propósito: o de narrar, contar histórias, e o de relembrar e desenterrar a história com h maiúsculo. A obra de ficção representa assim uma forma de testemunho e a escritora, uma "testemunha do seu tempo", nas palavras de Lygia Fagundes Telles (37). Para Machado, a literatura -e em especial a prosa de ficção- ocupa um espaço privilegiado graças à sua capacidade de representar, examinar e questionar aquilo que chamamos a "realidade", particularmente en épocas históricas quando outras formas de discurso narrativo recusam ou são impossibilitadas de realizar o mesmo. 
Em uma palestra mais tarde publicada em espanhol, a escritora afirma: "la literatura, por hacer un uso estético de la palabra, experimenta con lo que aún no se ha dicho, inventa algo nuevo, propone prototipos", ao contrário de uma produção narrativa da cultura de massas, que sustenta a consolidação do status quo (Machado, "Por uma cultura"121). Nesse mesmo texto, a autora discute várias formas de censura e autocensura que atuam mesmo em regimes democráticos, quando "los intentos de silenciar al otro generalmente se presentan de una manera camuflada y sutil" ("Por una cultura" 121). Quer em estados de repressão, quer durante períodos de ventos democráticos, a censura -seja ela, oficial e explícita ou oficiosa e dissimulada-coloca em risco o pensamento crítico e a dissensão, consequentemente pondo em cheque a própria caracterização e teor da "verdade". Esta questão, sobre o caráter e ética do que seja a verdade, tem ocupado a narrativa de ficção de Machado, tanto suas obras infanto-juvenis como seus romances para adultos. Por sua vez, o ethos do que se entende como verdade articula-se sobre a dialética memória-esquecimento, outra constante da obra da escritora e passível de moldar nosso entendimento da história e identidade nacionais.

Tal como os romances de Callado, a ficção de Machado oferece uma compreensão da história e do momento político distinta ou alternativa àquela encontrada na historiografia oficial ou nos grandes meios de comunicação. Seus romances justapõem a história nacional à história pessoal de seus protagonistas, representando eventos históricos e políticos através da perspectiva de personagens "menores" que se encontram às margens desses mesmos eventos. Além disso, a autora frequentemente entrelaça a história de vários personagens, como em Canteiros de Saturno (1991), e até períodos históricos diferentes, como é o caso de $O$ mar nunca transborda (1995). Neste caso, o passado histórico serve para iluminar e problematizar o momento presente, aliás como acontece em Memórias de Aldenham House de Callado. Como Callado antes, Machado tece um discurso polifônico que lhe permite "relativizar o conceito de verdade" (Vieira 46) e questionar a "verdade" veiculada pelo discurso oficial e pelos meios de comunicação.

Em Infâmia, romance de 2011, Machado denuncia o jornalismo "mau-caráter" e a "execração dos inocentes" na mídia, poderosa o suficiente para moldar e deturpar a realidade para o público leitor. O romance é baseado no caso do caseiro Francenildo Santos Costa que em 2006 foi vítima de retaliação por ter testemunhado contra Antonio Palocci, ex-Ministro da Fazenda do governo Lula. No romance, Custódio, um humilde funcionário público, tendo suspeitado corrupção e fraude na repartição onde trabalha, tenta comunicar suas suspeitas aos seus superiores mas acaba sendo falsamente acusado de apropriação indevida, e essas acusações vão se espalhando, fazendo com que ele seja considerado culpado sem chance de defender-se. Aqueles que o acusam, funcionários públicos graúdos, contam com o apoio da mídia, enquanto que Custódio é publicamente acusado e humilhado por uma rede de intrigas de proporções kafkianas.

Infâmia relata "o assassinato moral de Custódio" (262), um processo de aniquilamento, "em praça pública", de seu caráter e integridade, o qual pouco a pouco

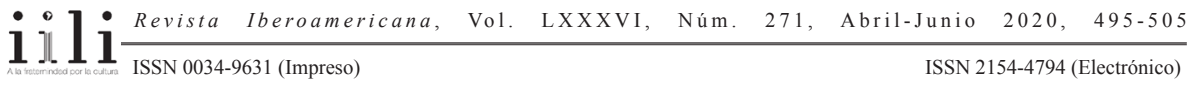


"vai despojando-o de alguma coisa essencial a sua dignidade. Um Jó sem fé. Sem esperança. Sem justiça. Sem” (Machado, Infâmia 271). Tal como o profeta bíblico a que o romance se refere, Custódio é vítima de uma intriga que lhe rouba amigos, emprego e até a saúde. Sua vida é destruída por um sistema político que, embora em tempos de governo democrático, funciona ainda como em um estado de exceção, não oferecendo ao cidadão comum a proteção legal e a justiça que são de seu direito.

Além da trama em torno do drama vivido por Custódio, Infâmia apresenta também outro núcleo narrativo em torno de Manuel Soares Vilhena, um velho embaixador aposentado, sua esposa e neto. De fato, o embaixador é o elo entre as duas tramas e dois dramas: o de Custódio e o da filha de Vilhena, Cecília, cuja morte inesperada o embaixador e sua família lutam por aceitar. Enquanto lidam com a dor da perda da filha e mãe, Vilhena, a esposa e o neto vão juntando as peças de um quebra-cabeças. O que desvendam é o envolvimento em sua morte do marido de Cecília-ele também diplomata-e os abusos e indignações a que a submetia. A máscara do diplomata refinado e respeitado esconde o rosto do marido abusivo, infiel e ambicioso que controla sua mulher e usurpa seus bens, finalmente levando-a ao suicídio. Esse pequeno drama doméstico tem também dimensões políticas, pois reflete a desigualdade entre os gêneros, a anuência da sociedade como um todo e, mais uma vez, a falha da justiça em proteger os mais fracos: "As leis, os costumes, o bom-tom teciam uma teia a seu [de Cecília] redor, onde ela estava presa à mercê da aranha. Como denunciar seu calvário e enfrentar quem estava seguro de poder contar com a impunidade?” (Machado, Infâmia 139).

Por outro lado, o caso de Custódio exemplifica de maneira mais explícita a infâmia nos bastidores políticos e seu impacto na vida do povo que, às margens do poder, são entretanto testemunhas dos fatos e da história nacional, embora tenham suas vozes silenciadas. Tanto a situação de Custódio como a de Cecília ilustram o que Michel Foucault caracteriza como "the general functioning of an apparatus of truth" (73), e a nulificação do indivíduo por esse aparato. Em ambos os casos, vê-se a valorização do poder masculinista, político, social e econômico, em detrimento dos direitos do cidadão e da pessoa humana. Custódio e Cecília são roubados de sua subjetividade e agência; difamados em público como desonesto um, e desequilibrada mental a outra, veem-se excluídos de suas relações sociais como consequencia da manipulação da verdade pelos detentores do poder. Segundo Foucault, "'Truth' is linked in a circular relation with systems of power which produce and sustain it, and to effects of power which it induces and which extends it. A 'regime' of truth" (74), dentro do qual "truth is already power" (75).

Em Infâmia, como em outros de seus romances, Machado problematiza a questão da "verdade" e não só denuncia sua manipulação pelo poder e pela mídia, como também retrata o dilema que enfrenta o público mais avisado: “[...] como saber quais as perguntas não formuladas pelos entrevistadores? Quais as pistas ignoradas pelos repórteres, as dúvidas não levantadas pelos comentaristas? Quais as ressalvas não feitas,

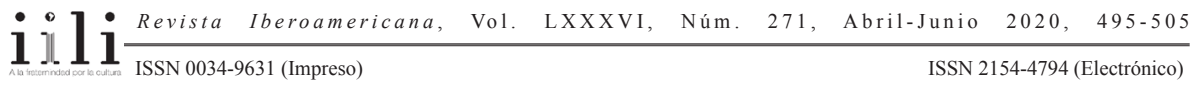


os indícios não seguidos?” E ainda: “Como distinguir um fato de uma versão? Como saber até onde acreditar na mídia?” (Infâmia 55-56). Este o retrato da imprensa na época contemporânea, em tempos de pós-verdade ou "alt-truth" ("verdade alternativa"), quando a verdade dos fatos torna-se praticamente irrelevante, e o que conta é a versão dada pelo instante midiático. Neste sentido, o romance de Machado questiona também o papel do público leitor e o do intelectual. Este aparece na figura do velho diplomata, íntegro mas vivendo em sua torre de marfim construída de ideais que já não correspondem à realidade distópica da sociedade contemporânea. A autora relembra também a seus leitores da nossa responsabilidade em questionar a "verdade" e as várias formas de discurso que alegam representá-la. Antes de tudo, Infâmia deixa claro que não se pode permanecer passivo ou calado, ao citar Umberto Eco na epígrafe da segunda parte do livro: "Também os leitores devem assumir a própria responsabilidade" (236).

Para Machado, assim como para Callado, autores e leitores complementam-se dialeticamente na função de trazer a mensagem da obra literária à plena fruição. $\mathrm{Na}$ obra destes dois escritores encontra-se concretizada a ideia de que a literatura, e em particular a prosa de ficção, preenche uma lacuna significativa, tanto durante períodos de governos ditatoriais como em épocas quando a democracia corre o grave risco de tornar-se uma "alt-democracia", quando os valores democráticos podem tornar-se irrelevantes nas mãos dos governantes. A literatura, segundo Machado, trata "dessas fronteiras ambíguas entre o verdadeiro e o falso" (Infâmia 174) e ao guiar-nos pelos interstícios que separam a verdade da inverdade convida-nos à reflexão crítica è̀ melhor compreensão do custo humano que os desmandos sociais e políticos acarretam. Neste sentido, cabe lembrar o comentário de Beatriz Resende sobre a ficção de Machado: "O mundo da arte, da literatura, pode, por sua própria condição de mediadora do real, pelo exercício de formas diversas de recriação, romper com os círculos viciosos que acusações e infâmias provocam, nos levando a pensar, a sentir, a partilhar emoções" (Resende 100).

Aficção narrativa permite a reflexão crítica sobre a realidade, não porque represente os fatos, mas sim porque os ficcionaliza, trabalhando assim com uma ampla gama de possibilidades, e exprimindo perspectivas múltiples sobre as relações de poder e o jogo de máscaras que constantemente têm lugar na sociedade. A literatura é, portanto, uma forma de intervenção na esfera política capaz de expor "the fictions of official history" (Schaffer e Smith 4). As obras romanescas de Antônio Callado e de Ana Maria Machado salientam "a importância de contar, narrar, fixar para não deixar esquecer e para tentar conter a repetição do mal" (Machado, Infâmia 142). Nos romances destes dois autores brasileiros, em épocas distintas mas tão semelhantes, fica comprovado o poder da narrativa de ficção, especialmente quando a distinção entre a verdade e a mentira, a integridade e a infâmia, insiste em permanecer nebulosa.

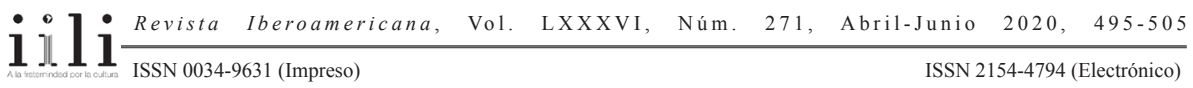




\section{OBRAS CITADAS}

Callado, Antônio. Memórias de Aldenham House. 1989. Rio de Janeiro: José Oympio, 2015.

Sempreviva. 1981. Rio de Janeiro: Nova Fronteira, 1982.

Dalcastagnè, Regina. "A personagem do romance brasileiro contemporâneo: 19902004." Estudos de literatura brasileira contemporânea 26 (2005): 13-71.

Foucault, Michel. "Truth and Power." The Foucault Reader. Paul Rabinow, ed. New York: Pantheon, 1984. 51-75.

Leite, Lígia Chiappini M. "Quando a pátria viaja: uma leitura dos romances de Antônio Callado". O nacional e o popular na cultura brasileira. Artes Plásticas. Literatura. Carlos Zilio, João Luiz Lafetá e Lígia Chiappini M. Leite, eds. São Paulo: Brasiliense, 1983. 129-234.

Machado, Ana Maria. Infâmia. Rio de Janeiro: Objetiva, 2011.

y Graciela Montes. "Por una cultura de resistencia". Literatura infantil: creación, censura y resistencia. Buenos Aires: Sudamericana, 2003. 113-22. 2005.

Resende, Beatriz. "Política, ética e estética na obra de Ana Maria Machado". Brasil/ Brazil 49 (2014): 83-102.

Ribeiro, Edgard Telles. O punho e a renda. 2010. Rio de Janeiro: Record, 2014.

Sapriza, Graciela. "Memoria y memorias de mujeres en el relato de la dictadura(Uruguay, 1973-1985)". Gênero, feminismos e ditaduras no Cone Sul. Joana Maria Pedro e Cristina Scheibe Wolff, eds. Florianópolis: Mulheres, 2010. 94-114.

Schaffer, Kay, e Sidonie Smith. Human Rights and Narrated Lives. The Ethics of Recognition. New York: Palgrave MacMillan, 2004.

Valente, Luiz Fernando. "Re-membering the Nation: Antonio Callado's Sempreviva." Romance Notes 42/1 (2001): 79-86.

Vecchi, Roberto, e Regina Dalcastagnè. “Apresentação". Estudos de Literatura Brasileira Contemporânea 43 (2014): 11-12.

Vieira, Ilma Socorro Gonçalves. "O diálogo entre literatura e história na obra de Ana Maria Machado”. Trança de histórias: a criação literária de Ana Maria Machado. Maria Teresa Gonçalves e Benedito Antunes, orgs. São Paulo: UNESP, 2004.3552.

Telles, Lygia Fagundes. A disciplina do amor. Rio de Janeiro: Nova Fronteira, 1980.

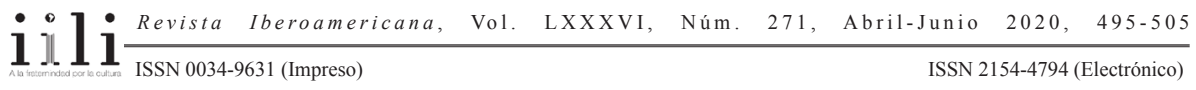


Palavras-chave: Romance político; verdade e poder; Antônio Callado; Memórias de Aldenham House; Ana Maria Machado; Infâmia

Recebido: $\quad 5$ março 2017

Aprovado: $\quad 15$ maio 2017 
